\title{
PERFIL DE CÉSAR CIGLIUTTI (1957-2020), PRESIDENTE DE LA COMUNIDAD HOMOSEXUAL ARGENTINA
}

\author{
Facundo R. Soto
}

En 1984, César Cigliutti, luego de graduarse como profesor en Letras, se incorporó a la CHA (Comunidad Homosexual Argentina), institución a la que perteneció hasta 1987. En 1991 fundó, junto a Carlos Jáuregui y otros activistas, GaysDC (Gays por los Derechos Civiles).

En 1987 llevó adelante Stop SIDA, la primera campaña de prevención dirigida a la población LGBTI realizada en Argentina. En 1992 fue cofundador de las Marchas del Orgullo en la Ciudad de Buenos Aires. Al regresar a la CHA, fue elegido como presidente y ejerció ese cargo desde 1996 hasta su fallecimiento.

César fue uno de los impulsores del Art. 11 de la Constitución de la CABA (Ciudad Autónoma de Buenos Aires), que reconoce el derecho a ser diferente y a la no discriminación. Luchó por la derogación de los Edictos Policiales y fue uno de los pioneros en la lucha por los derechos de las familias LGTBIQ+. En el año 2000 presentó el proyecto de Ley de Unión Civil de la Ciudad de Buenos Aires, que fue el primer reconocimiento de nuestras parejas en toda Latinoamérica y el Caribe. Realizó la primera unión civil junto con su pareja en 2003; impulsó las pensiones por viudez; se casó en España en 2008 y reclamaron juntos ante la justicia argentina el reconocimiento de ese matrimonio en 2009. Fue uno de los impulsores de la Ley de Matrimonio Igualitario, la Ley de Identidad de Género, la derogación de artículos represivos de códigos de faltas provinciales, la reforma de la resolución del Ministerio de Salud de la Nación que impedía donar sangre a personas de la Comunidad LGTBIQ+ y la reforma de la ley antidiscriminatoria nacional, entre otras normas. Fue nombrado ciudadano ilustre de la Ciudad de Buenos Aires en 2011. Nació el 5 de marzo de 1957 en Concepción del Uruguay, provincia de Entre Ríos, y falleció el 31 de agosto de 2020 en la Ciudad de Buenos Aires.

Contó César:

La idea de la marcha se le ocurrió a Carlos Jáuregui, estábamos los dos solos en casa, y él propuso hacer una macha con la palabra «dignidad». Porque la palabra «dignidad» es la que se había usado durante muchos ańos en la Argentina para esta fecha. Y yo le dije: «Mirá, Carlos, ya es hora de usar la palabra orgullo; porque la traducción de Pride en inglés es Orgullo. Además, porque orgullo es el antónimo de la vergüenza. Y la vergüenza es el sentimiento que quisieron imponernos por tener nuestra identidad». Carlos lo redondeó y estableció la frase: «El orgullo es la respuesta a esa vergüenza que intentaron imponernos». En cuanto a la dimensión de la marcha, en esa época, nosotros hacíamos volanteadas en los lugares de

DOI: https://doi.org/10.25145/j.clepsydra.2021.21.13

RevisTa ClepsYdra, 21; marzo 2021, pp. 295-304; ISSN: e-2530-8424 
encuentro y nuestra propia comunidad nos decía: «¿Pero orgullo de qué? ¿Por qué tenemos que sentir orgullo?». Hubo que explicarlo. También en la Primera Marcha, que tuvo mucha difusión, los periodistas cuestionaban la palabra «orgullo». Tuvimos que salir a explicarlo y de a poco ese sentimiento fue arraigándose hasta constituirse en un sentimiento de identidad. A 28 ańos de esa marcha el Orgullo lo expresamos de una manera tan evidente que estamos muy contentos de haber trabajado en ese sentido».

Pero ¿quién fue en verdad este luchador aguerrido de la comunidad LGBT y los derechos humanos?

\section{EL ACTIVISMO DE CÉSAR}

César empezó a llevar la voz cantante de las Marchas del Orgullo y siempre lo hizo de una forma amistosa, de igual a igual, evitando la jerarquía de superioridad. No podía diferenciarse el César amigo del César militante, aunque fuese la primera vez que alguien hablara con él; estas dos facetas iban juntas en él. Los que entraban a la CHA pasaban a ser amigos de César y no activistas. Había gente que trabajaba -que no era mucha- y otra -la mayoría - que tomaba a la CHA como un lugar de encuentros o un pub; dada la soledad que todavía seguía existiendo para relacionarse. No era fácil decir, todavía por aquellos días, que uno era gay o lesbiana, y conocer gente que compartiera los mismos gustos o inclinaciones, tampoco era sencillo, sobre todo porque todavía se seguía ocultando la personalidad de cada unx, por temor a ser rechazadx. Diego Trerotola reflexiona: «Coincidíamos con César en que el activismo no tenía que ser solamente un discurso áspero, también tiene que ser maricón. Tiene que tener la belleza de lo maricón que César siempre defendió».

César no practicaba la idea de referente. A Carlos Jáuregui lo definía como un hermano de la vida. El activismo para César era politeísta y ecléctico. Veía importancia, paramilitar, en la literatura, en la prensa, en la pintura, en los medios y aprendía de todo y de todos. Sabía que podía aprender en todo y en todxs, sin importarle la escala social donde esa persona estuviera. Agrega Trerotola:

No solo Carlos Jáuregui le enseńó, sino que de la CHA aprendió mucho. Por eso él nunca trabajó de viuda de Carlos. Era su amigo y con él aprendieron a vivir en comunidad. Toda la gente que pasó por la CHA le enseñó algo a César. La $\mathrm{CHA}$, desde que yo estoy, fue y es horizontal. César escuchaba mucho. Lo que cualquiera decía, una persona trans que recién había ingresado, yo, una lesbiana, alguien del área jurídica o de salud, él la escuchaba. Construía discurso a partir de la voz colectiva. Siempre trabajó sobre el consenso, porque entre todxs hacíamos los discursos. César fue la figura pública, que se mostró más que otrxs, era algo consensuado y creado por todxs. César nunca creyó en las autoridades, por más que mediáticamente se convirtió en una autoridad, en una voz. Y no se bancaba el autoritarismo; fue muy consecuente. En mis 24 años de militancia en la CHA siempre lo vi horizontal.

La idea de César sobre la CHA era la de hacer un activismo comunitario. Cuando se fue de la asociación y fundó con Jáuregui GaysDC, retomó la idea de 
hacer un trabajo comunitario, en torno a un referente. Cuando le preguntaban si él era el presidente de la CHA acostumbraba a decir: «En la CHA no hay rey, somos todas princesas".

Trerotola, que forma parte de la CHA desde hace 25 ańos, dice: «Yo que soy medio anarco, si la CHA hubiese sido verticalista no duro ni un día. César incorporaba las voces de todas las personas que entraban. Las escuchaba, las entendía... Unía ideas de otras personas a su discurso. Pensaba colectivamente».

Valeria Paván cuenta: «Nunca nadie le cortó el teléfono o le cerró la puerta a César. Muchas veces fui corriendo a decirle que necesitaba una reunión con no sé quién, que no teníamos ningún contacto y él me decía: 'llamamos por teléfono, mamita'. Y así lo hacía. Llamaba por teléfono y nunca dejaron de responderle; eso es verdad. Por la $\mathrm{CHA}$, una organización que tiene 36 años, que le da un peso importante, pero esto de la mano de César se potenció». Paván coincide con César en que lo que hacen en la CHA no es activismo sino militancia: «La militancia de César era una actividad ininterrumpida y la militancia tiene que ver con eso, con un compromiso que empieza desde la mañana».

Para César la CHA era una comunidad; él creía en la comunidad. La CHA era la comunidad utópica que él construyó. César se enojaba con la gente que no hacía las cosas con sentido comunitario sino de forma individualista. «El activismo es hacer cosas en contra de la gente que hace las cosas mal», dijo César convencido.

\section{HS. X 7}

El activismo de César era de 24 horas. Alguien que no conoce el activismo LGBT no entiende por qué en el mundo gay, en esa época, era más de noche que de día. Las razias en los boliches eran a las tres de la madrugada. A las travestis las detenían en la zona roja a las cinco de la mañana, no a las tres de la tarde. Había un protocolo para atender el teléfono fijo. Cuando hacían una razia en los boliches las locas corrían para agarrar "La otra guía»" donde figuraba el número de teléfono de la CHA para contar y denunciar lo que estaba pasando.

Cuando los policías irrumpían en los boliches gais, como lo hacían frecuentemente en Contramano, para iniciar las razias, la gente se agarraba de las manos y cantaba el «Himno Nacional Argentino» a los gritos, intentando tapar la música de fondo, que terminaba interrumpiéndose. En el desconocimiento, y por la fuerza, los lazos de hermandad y protección se empezaban a poner en marcha. La letra del «Himno Nacional» dice en un momento: «Libertad, libertad, libertad...»; el reclamo de libertad que se estaba pidiendo a los gritos cuando los uniformados irrumpían en un bar privado a censurar la posibilidad de contacto y unión que podían tener dos personas -o más- del mismo sexo.

\footnotetext{
1 «La otra guía», subtitulada «Primera guía de servicios para gais y lesbianas», es una revista de distribución gratuita que se publicó en Buenos Aires desde 1997 hasta 2017.
} 
Trerotola recuerda: «Yo, una noche, estaba durmiendo en la sede y alguien que llamó me dijo una frase que me shoqueó. Me dijo un puto viejo desde un pub, Gasoil: 'Están haciendo una razia como en la peor época de la dictadura. Están pidiendo documento e insultando a la gente'. La policía siempre hacía eso».

El protocolo consistía en:

1) Pedirle a la persona el número de la comisaría que había entrado al lugar para efectuar la razia. Si no lo sabía tenía que averiguarlo, dado que se trataba de una información relevante.

2) Desde la CHA había que llamar a la comisaría pidiendo explicaciones acerca de los motivos por los cuales se estaba llevando a cabo la razia en ese lugar; dejando en claro que la $\mathrm{CHA}$ era una organización que estaba cuidando a las personas -en muchos sentidos-, sobre todo a nivel legal. "Que supieran que estábamos vigilándolos, a la policía, porque si no ellos podían torturarlxs; y si nosotros no llamábamos a los medios la información nunca salía», agrega Trerotola.

3) El tercer paso del protocolo consistía en que la persona que atendía el teléfono en la CHA tenía que contactarse cuanto antes con lxs abogadxs, sin importarle la hora que era; generalmente se recibían este tipo de llamados después de las tres de la mañana y hasta las cinco, para comunicarles que se estaba haciendo una razia en el bar o boliche y la dirección donde estaban. La persona de la CHA tenía que pedirle la dirección del lugar y que averiguaran -sí o sí- qué comisaría estaba llevando a cabo el procedimiento.

4) Llamar a la comisaría y pedir el nombre de las personas detenidas (porque ese era uno de los objetivos de las razias, además de amedrentar y sembrar miedo: llevarse personas detenidas). "Como a mí, al principio no me querían dar esta información, cuando llamaba por teléfono, por más que les dijera que era un miembro de la CHA, empecé a hacerme pasar por un abogado; tenía el nombre de uno, su número de matrícula y documento. Yo solía decir que era el doctor José Luis Pizzi, y les explicaba que estaba defendiendo a esas personas porque era uno de los abogados de la CHA, y que me tenían que decir el nombre y el apellido de cada una de las personas detenidas", dice entre risas Trerotola.

5) Si el operativo era grande había que llamar a los medios de comunicación, sobre todo a los canales de televisión, porque brindaban mayor visibilidad y exposición del tema que los diarios y revistas. El abogado de la CHA que se presentaba durante la razia representaba a toda la gente damnificada, y la policía -al enfrentarse con un letrado- lo tenía que respetar.

«Si lo mostraban por la tele trataban menos mal a lxs detenidxs que si no había nadie filmando. No había celulares (móviles) en esa época. La policía tenía que saber que había alguien que se interesaba por las personas que se habían llevado, sobre todo por las travestis, porque las familias no solían preguntar por ellas; y a las travestis se las llevaban porque sí, porque eran travestis», recuerda Trerotola. 
Una de las cosas que lxs activistas de la CHA más respetan de César es que él hacía todo: desde proponer escribir un texto hasta pedir las pizzas, cortarlas y ponerlas sobre los platos, sin ninguna actitud de superioridad a pesar de ser el presidente de la organización.

\section{SU FORMA DE SER}

Durante el 2019 me estuve reuniendo con César en bares con la idea de escribir su biografía política -que ya estoy terminando-, para la cual mantuvimos numerosos encuentros con agradables e iluminadoras charlas donde César nunca perdió la calma y jamás se mostró displicente para hablar de ningún tema.

Haber ido a la CHA me cambió la vida. Sí, pero lo principal era Carlos (Jáuregui). Realmente éramos hermanas... Incluso mi pareja, Marcelo, se ponía celoso. Decía que estábamos juntos todo el tiempo, en el boliche, acá, allá. Todo el mundo pensaba eso. Uno, con el que salí un tiempo, me decía: 'No sabés lo difícil que es aceptar eso, por mí, por Carlos y por parte del entorno', y a mí no me importaba, que no lo entendieran o no, a mí me encantaba lo que hacía. Éramos amigos, como hermanas... Sigue mi energía puesta en la CHA con la misma intensidad que antes. No me imagino una vida sin militancia.

Si tuvieras que poner un enemigo, ahora, en términos de lucha y militancia, ¿quién sería ese enemigo?, ahora que los dinosaurios desaparecieron, o casi...

La interna dentro del movimiento es lo peor. Antes, las peleas eran de putos con lesbianas y con algunas travestis... Pero lo peor siempre fue la interna porque la lucha es más intensa. Te conocés más, las debilidades y las fortalezas. Te duelen más las traiciones. Hay una cuestión de arrebato histórica. Vos que jugaste en equipos de fútbol gay, cuando yo empecé en la $\mathrm{CHA}$ como presidente, un director técnico me decía que a él le gustaba la CHA de Carlos; con lo cual me estaba diciendo que César era un maricón y que a él esa figura no lo representaba... Siempre es eso, lo más salvaje. Éramos amigas todas: las lesbianas, las travestis... Las reuniones de militancia eran entrar saludando a todo el mundo pero después viene la usurpación, que es no reconocer las identidades o instituciones, no digo yo las mías, digo en general, o liderazgos como el de Lohana. En la última marcha se armó un kilombo bárbaro porque censuraron un video de Lohana, un grupo decía que no les quería dar el gusto de pasar ese video... En fin... la cortamos. Usurpaciones de todo tipo. Yo conozco la cocina porque soy un sobreviviente. Estuve cuando empezaron todas las organizaciones, AMMAR, las organizaciones de lesbianas, Las Fulanas, por ejemplo, alquilaron la primera casa con la garantía de mi casa. Yo fui con la escritura a la inmobiliaria... Hay un montón de cosas que la gente no se acuerda y eso me parece una falta de pudor impresionante. Además, yo nunca hice público un montón de cosas... Cuando estuvo ese lío en el INADI, que estaba la interventora entrante y el saliente ahí, que aparecieron en todos los medios, me llamaron a mí de los canales y los diarios para que contara lo que pasaba. Y yo dije: 'Mirá, no hay ningún conflicto, se pelearon y la presidenta en el mismo día intervino el INADI 
y el tema está solucionado', eso dije a Clarín y a La Nación. Pero te imaginás todo lo que podría haber contado...

César le dedicó toda su vida a la CHA, resignó tener hijos y la fantasía de pintar y escribir cuentos infantiles para abocarse de lleno a la organización. Llegó a comprar telas, que nunca pintó (a excepción de un Ícaro caído, a medio terminar, que estuvo expuesto durante muchos años en una de las sedes de la $\mathrm{CHA}$ ).

César se levantaba temprano y preparaba café. Llenaba una taza y lo tomaba solo, mientras leía los diarios. Después partía, rápido, para su trabajo, donde hacía todo lo que tenía que hacer y si terminaba antes le dedicaba el tiempo restante a la CHA y al sindicato que había fundado, APERSES (Asociación Personal de la Seguridad Social), que se constituyó el 17 de mayo de 2006 como Asociación del Personal de la Superintendencia de Administradoras de Fondos de Jubilaciones y Pensiones (APERSAFJP) para representar los intereses de los trabajadores de la Superintendencia de Administradoras de Fondos de Jubilaciones y Pensiones (SAFJP) de todo el país. Allí, César ocupaba el cargo máximo de la comisión directiva, el de secretario general.

Antes de dormir, todas las noches, se acostaba en la cama y agarraba un libro. Leía rápido: podía empezarlo un día y al siguiente terminarlo. Le gustaba leer novelas y cuando descubrió la ciencia ficción se le abrió un mundo nuevo que tuvo incidencias en su vida política. Durante su hora de almuerzo, en el trabajo de la AFJP, César solía salir a recorrer las librerías de la avenida Corrientes y explorar autores o títulos nuevos. Disfrutaba de aprovechar las ofertas de los libros que reposaban en las mesas de saldos y descubrir nuevos géneros.

Solía ser muy bondadoso. No era de acumular objetos - no tenía un solo cuadro en la casa- ni fetichista con las cosas; por el contrario, era muy práctico y despreocupado de los objetos materiales. Era empático y funcionaba como espejo para la mayoría de las personas con las que interactuaba, de manera que se generara un clima de confianza y afinidad que al poco tiempo se volvía recíproca.

Las acciones que no tenían que ver con una estrategia política le salían de manera espontánea y las vivía así, en estado puro, sin reflexionar sobre lo que le acontecía. Vivía el presente con intensidad y cambiaba de escena y escenario en la medida en que el tiempo pasaba, sin quedarse pegado al pasado. Eso no invalidaba que contara con una memoria activa y que siempre se le desprendiera algún recuerdo o anécdota de Carlos. Muchxs lo recuerdan como «bonachón», otrxs: «esa hermandad marica que tenía con nosotrxs». Era muy considerado con la gente y nadie puede relatar alguna situación de traición o mentira; esto es destacable para una persona que ocupaba un cargo político en una organización, porque podría pensarse casi como la excepción que confirma la regla acerca de lo que ya conocemos de los políticos. No permitía la ofensa ni la no reciprocidad de afecto.

En cuanto a características personales era bastante decoroso. Se podía reír hasta las lágrimas de algún relato semi -o explícitamente- porno que le contaba algún amigx, pero él no solía construir este tipo de relatos, porque parecía que no estaba en su esencia usar palabras lúmpenes, así como tampoco relatar historias de su vida sexual, porque priorizaba el amor en las relaciones. No por eso se 
espantaba de las relaciones sexuales que no estuvieran ensambladas bajo el concepto de amor.

Era desprejuiciado y abierto. No concebía el casamiento heterosexual como algo positivo por las restricciones e imposiciones que tiene el matrimonio cristiano. Estaba a favor de las parejas abiertas y del poliamor, como la decantación de un pensamiento filosófico y de una experiencia práctica que podía ver en el día a día. La cavilación era mucha -y muy intensa- sobre sus actos políticos y los efectos de los mismos. Era de cuidar los vínculos y que nadie agrediera a nadie. Su ideología era la de «la marica» y «la comunidad», como ejes que lo atravesaban para pensar políticas y llevar a cabo sus actos.

Uno de los valores que César más apreciaba era la lealtad. A las personas que no le respondían con actos leales, César no las quitaba de su vida sino que las mantenía de otra manera, esgrimiendo una distancia que, si bien no era evidente, les hacía sospechar que algo se había roto. Solía expresar con palabras afectuosas su bienestar -que se volvía recíproco- con sus amistades. Era frecuente escucharlo decir: "Te quiero mucho" después de un beso o un abrazo, frente a una despedida cotidiana; aunque fuese a ver a esa persona en la semana.

La sexualidad de César se construía a partir del afecto, la seducción y el romance. Es por eso que no resultaba frecuente escucharlo expresar situaciones eróticas o sexuales como suelen hacer muchas locas en sus relatos. El sexo en sí, como algo salvaje y despersonalizado, no era algo que lo erotizara. No entraba al túnel (cuarto oscuro) de Búnker, pero no por una cuestión de principios, sino porque no le producía placer ni interés. En César el interés pasaba por el amor.

La personería jurídica de la CHA, o sea, el primer derecho reconocido, conquistado y ganado -el de derecho de asociarse- y la visibilidad pública y masiva de las sexualidades e identidades disidentes gracias a la creación de la Marcha del Orgullo, fueron los dos hitos que a César más lo enorgullecían como logros que había obtenido con la CHA.

Ester, la empleada doméstica que trabajó en su casa durante muchos años, cuenta: "César era muy ordenado, limpio y prudente. Le encantaba leer. Súper buena persona, le gustaba ayudar mucho a la gente. Le gustaba hacerme regalitos, ayudarme. Yo tengo un hijo con síndrome de Down y él -que lo sabía-compraba golosinas para él y se las mandaba a través mío. Era de hacer muchos regalos. Muy agradable. No dejaba nada desordenado. Yo charlaba con él, le contaba mis cosas, mis problemas, y él me daba consejos. Le gusta charlar con la gente. También me ayudaba económicamente. Él nunca tuvo problema en darme, en prestarme. Fue como un padre para mí y para mi hijo. Nunca se olvidó de nosotros. Cuando él sabía que yo iba, comenzaba a prepararme algún paquetito para darme. Jamás me dejó hacerle la cama. Siempre la hizo él a su manera. Él cocinaba y hacía comida para mí también. Me preparaba un té y me ofrecía todo lo que tenía para comer. Tenía a disposición la casa sin problemas y la libertad de sentirme bien, me trataba como si fuese alguien de su familia».

María Laura Oliver, miembro de la CHA, dice: «Quiero rendirle homenaje todos los día de mi vida a César, porque me enseñó muchísimas cosas. Me tendió la mano. Me dio casa y comida. Me dio la libertad que hoy siento. Me dio la posi- 
bilidad de hablar ante un medio de comunicación, de televisión o dar un reportaje en un diario. Poder decir lo que una realmente siente. No hay que elaborar un discurso. No es la palabra trabajada, no; es lo que uno realmente siente y dicho de manera sencilla y fácil, que sea entendible».

El afecto y el amor eran lo que lo movilizaba a César; y eso creo que era su mayor virtud. También los principios que tenía..., su convicción; yo aprendí eso de César. Aprendí a ser activista con César y Carlos - pero sobre todo con Césarporque Carlos murió en 1996 y lo conocí tres años, pero igual fue hermoso. No los movilizaba el odio, la bronca o el rencor, sino el afecto y el amor. Ellos podían transformar eso en otra cosa. César me enseñó a tener una visión histórica del activismo. Me enseñó con los hechos que no somos solamente nosotros, que hay un pasado del que nos valemos: la militancia. César tenía un interés por ayudar, sin ningún interés más que fortalecer la autonomía de los grupos. Ellos estaban felices por el colectivo Arco iris, no lo veían como una amenaza; eso uno lo sentía y era maravilloso.

Valeria Paván: «César era una persona cálida y amorosa. Su humanidad es lo primero que te llega, inmediatamente, y te toma. Es imposible no verlo como un referente político. En la organización, en las asambleas, se veía la capacidad de hacer lecturas políticas y en función de esas lecturas implementar acciones para llevarlas a cabo. Para mí, César siempre fue un líder. Fue nuestra figura referencial en la organización, aunque desde afuera se veía raro. Era un consenso unánime, desde la CHA, que necesitábamos que César fuese el presidente y no nos importó que ese puesto importante estuviera un tiempo importante sin rotación. No la había, porque no queríamos que la hubiera, existía en otros puestos, pero lo votábamos a él, cada vez que había que renovar autoridades. Una organización realmente democrática y horizontal».

A César le gustaban la mutación y el cambio. Es decir, no cristalizarse en algo -ya sea un autor, una propuesta o una definición-, sino cambiar. Cambiar permanentemente, como David Bowie lo hacía desde su imagen hasta su música, era lo que a César le interesaba. "Estar del lado de la diversidad a pleno», solía decir. Se asombraba de las cosas que le gustaban mucho, como, por ejemplo, ver una flor que atrapara sus sentidos. Y el asombro se acrecentaba, por ejemplo: el color responde a una pigmentación que tiene la flor para atraer a las abejas y que estas puedan polinizarlas.

César buscaba las palabras para comunicar, eligiendo las que tuvieran un significado en particular y además fuesen bellas. Algo de su formación de docente y del arte lo acompañaba las 24 horas del día. No le gustaban las frases hechas o los eslóganes. Buscaba las palabras que creía convenientes para lograr ser preciso y transmitir la idea de lo que quería decir y, también, en otras circunstancias políticas, encontraba las palabras adecuadas para ser deliberadamente vago.

A César no le gustaba el fútbol pero a su marido sí. Cuando Marcelo se sentaba en el sillón a mirar un partido, la respuesta de César era apagarle el televisor o cambiar de canal. Usaba la broma y los chistes como formas de comunicar su disconformidad o aburrimiento.

César solía definirse, políticamente, como «una marica básica». Soltaba la frase cuando alguien le preguntaba por un perfume en particular. Le encantaban 
las fragancias pero no se focalizaba en ninguna marca en particular. Tenía muchos perfumes, todos se los habían regalado. Alguna vez se compró alguno, después de haberse enamorado de la fragancia, pero no por la marca, a la inversa de las personas que eligen los productos por el reconocimiento social y la marca.

Una fantasía de César era retirarse del activismo, después de la muerte de su tío Horacio - a quien adoraba-, de su papá y de su mamá, pero la autopropulsión por los derechos vulnerados de las personas de la comunidad fue tan grande que después de un año de actividad volvió como el ave fénix, con toda la fuerza y energía.

Un día, en un café, después de pagar, con el sol sobre nuestras espaldas, me dijo: «Facu, a mí la militancia me salvó la vida. Volver a tener proyectos, proyectos con la CHA me hizo renacer. Hay que tener proyectos; es lo único que salva». De todas formas, la fantasía de retirarse de la militancia estaba y la de escribir cuentos para nińxs era la que ocuparía su tiempo y su interés, que siempre era por lxs demás: «darle algo lindo o hermoso a lxs otrxs». Escribió un cuento y diseñó otros, en relación con el tipo de escritura que quería para este proyecto: una escritura ágil y fluida, con frases cortas, replicando a su forma oral de narrar los hechos, a diferencia de los textos comunicativos, cargados de información, que escribía para la $\mathrm{CHA}$.

César tenía otra responsabilidad muy grande, la sindical. Era secretario de APERSES, el sindicato del ANSES que él había fundado. Durante una parte del día estaba preocupado por solucionar -también- las necesidades de sus compañerxs de trabajo. Era muy activo, inquieto, atento a todo lo que sucedía y muy sensible. Tenía sus plantitas, que cuidaba mucho y le encantaba verlas cuando le daban flores. Cuidar las plantas y el arte de la India le daba mucho placer.

Era una persona sin egoísmo, atenta a las necesidades que pudiera tener cualquier activista de la CHA, o empleado del ANSES, o personas del colectivo LGBT -en general- y con mucha generosidad ayudaba a la formación de nuevas sociedades civiles, por ejemplo, en el interior del país.

César creía realmente en la diversidad y en la promoción de muchas sociedades civiles. No estaba de acuerdo con hacer una CHA poderosa y exclusiva; por el contrario, estaba convencido de la riqueza que otorgaba la pluralidad, que se generaba desde todas las sociedades civiles.

Si veía a una persona muy vulnerada, no solo la ayudaba, desde escucharla hasta aportarle ideas y contacto, sino que muchas veces metía la mano en su bolsillo: la generosidad de César era algo auténtico y desinteresado.

Cuando unx es atacado o denunciado o acusado y no se lo puede resolver fácilmente, porque los hechos están perdidos, y no hay pruebas para contrarrestar los ataques, César decía: «¿Para qué pelear? No vale la pena. Hay que cuidar... Cuidar la memoria histórica».

César no cultivaba la envidia, era un sentimiento que no afloraba en él. El humor le permitía salir de algunas situaciones incómodas y construir a partir de las antípodas -la destrucción, que suele ser el arma de muchxs activistas-. Le gustaba alentar a la gente en la actividad que realizaba, por ejemplo, escribir. Si alguien le decía: «César, estoy escribiendo algo», él respondía: «Qué lindo, qué bárbaro». A veces, cuando quería a ayudar, lo decía explícitamente: «¿Querés algo de ayuda?». En cuanto a la rivalidad política decía: «La rivalidad bien entendida es inspiradora». 
Con César aprendimos que la dignidad es un valor intrínseco a todxs las personas -aunque a veces nos quieran hacer creer lo contrario- y ser distintxs a la norma hegemónica un orgullo. Con él nos liberamos, no un poco sino mucho más, porque César estaba ahí, para ayudarnos a reclamar por nuestros derechos y abriéndonos las puertas para que nos encontremos con nuestros placeres, sin prejuicios. César nos hace falta y lo extrañamos cada día que pasa un poco más. 